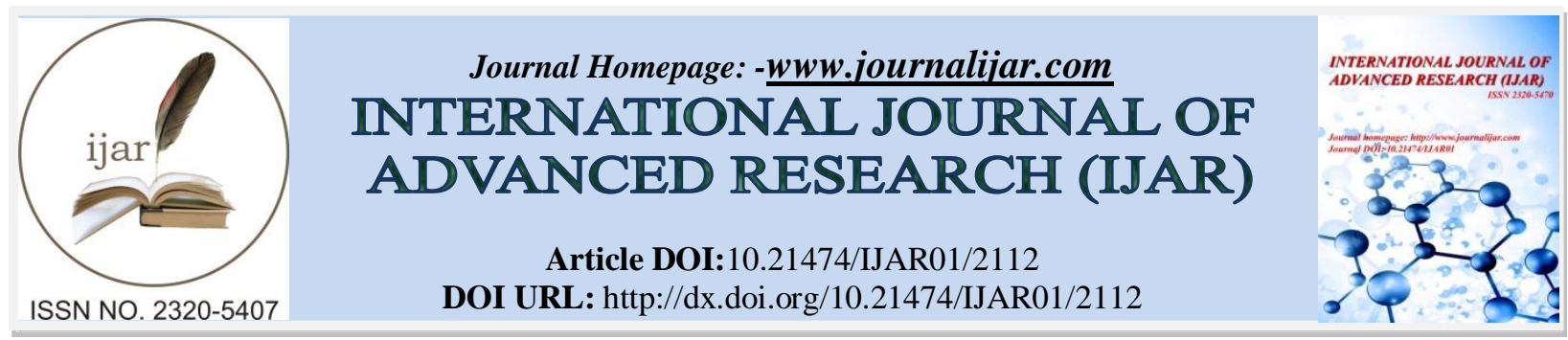

RESEARCH ARTICLE

\title{
SCREENING AND EVALUATION OF ANTIMICROBIAL ACTIVITY OF THYMUS VULGARIS USING IN VIVO AND IN VITRO METHODS
}

\author{
Yasser M. Kamel ${ }^{1}$, Amani A. Hafez ${ }^{2, *}$ and Wafaa H. Abd-Alla ${ }^{3}$ \\ 1. Department of Microbiology, Faculty of Medicine, Rabigh, King Abdulaziz University, Saudi Arabia. \\ 2. Department of Animal Health, Infectious Diseases Unit, Desert Research Center, Cairo, Egypt. \\ 3. Department of Medicinal \& Aromatic Plants, Desert Research Center, Cairo, Egypt.
}

\section{Manuscript Info}

Manuscript History

Received: 25 September 2016

Final Accepted: 27 October 2016

Published: November 2016

Key words:-

Thyme essential oil, S. aureus, Antibacterial activities, MIC and Thymol

\section{Abstract}

There is a great effort to discover plant-derived antibacterial against multi-drug resistant bacteria. The objective of the study to the possibility of organic production of Thymus vulgaris herb under sandy soil and investigate the in vitro and in vivo antibacterial activities of thyme essential oil that was analyzed and its constituents were identified by GC/MS. The major components were thymol $(45.15 \%)$ and p-cymene (25.31\%), borneol (5.06\%), myrecen $(3.42 \%)$ and $\alpha$ pinene $(3.21 \%)$. A Staphylococcus aureus-infected mice model was subjected to meet the study objective. The physiological, biochemical and histopathological markers of possible effects of this essential oil were studied using various standard methods. The extract had a significant effect on the number of viable Staphylococcus aureus recovered from spleen where 4MIC group was the best group in inhibiting the bacteria followed by $2 \mathrm{MIC}$ and $1 \mathrm{MIC}$. There were no side effects on vital organs observed even in using 4MIC dose. The obtained results indicate that the essential oil of thyme has the potential to provide an effective treatment for S. aureus infection. It is necessary to further investigate the interaction between the pathogenic bacteria and thyme essential oil and its impact on the development of resistance.

Copy Right, IJAR, 2016,. All rights reserved.

\section{Introduction:-}

Regarding the developing countries, traditional medicine considered the most important source of drugs that used for treating many types of infectious microorganisms. The rise of multidrug-resistant bacteria, expensive price of synthetic drugs and many adverse side effects are factors encouraged the pharmaceutical companies to investigate alternative sources to produce novel therapeutic agents. Medicinal plants have been considerable attention in this issue where these plants have the capability to produce a variety of secondary metabolite compounds (Jaber $e t$ al., 2012) that be consumed to protect themselves against the attack of different pathogenic microorganisms (Chaudhry and Tariq 2009).

Thyme (Thymus vulgaris) is a member of family Lamiaceae and locally known as 'Zaatar'. Since many decades, Thymus essential oil (EO) has been broadly used as a medicinal plant in Egyptian flock medicine, alternative medicine, and natural therapeutics. As a valuable medicinal plant, Thymus vulgaris possesses a wide range of biological activities including carminative, antispasmodic, expectorant, antiseptic, and antioxidative properties 
(Omidbaigi and Nejad 2000; Dapkeviciuset al 2002 and Vardar, et al., 2003). Common thyme contains 0.8-2.6\% volatile oil. The main constituents of thyme include thymol, carvacrol and flavonoids often thought to have an antibacterial effect (Barnes et al., 2002). Earlier work has been approved that essential oils of some plants display antimicrobial properties especially against pathogenic bacteria (Prabuseenivasanet al., 2006). This study was planned for estimating in vitro and in vivo antibacterial activities and possible side effects of essential oil of thymus vulgaris against Staphylococcus aureus (S. aureus) strain.

\section{Materials and Methods:- \\ Bacterial strains:-}

S. aureus strain operated in this work was obtained from microbiology laboratory, department of animal health, Desert Research Center.

\section{Collection and preparation of plant sample:-}

Thyme plant was obtained from Sekem farm in the desert of Belbais, Egypt. The collected plant was dried and stored in a dry place until extraction.

\section{Extraction process:-}

The dried plant was subjected to the hydro-distillation process for about 3 hours by using Clevenger apparatus as stated by European Pharmacopoeia (1996). Finally, the obtained essential oil (EO) was dehydrated in a desiccator containing anhydrous sodium sulfate and then stored in the refrigerator at $4^{\circ} \mathrm{C}$ until operated.

\section{Phytochemical analysis:-}

Gas chromatography mass-spectrophotometer analysis of thyme essential oil:-

The gas chromatography-mass spectrometry (GS-MS) analysis for oil samples from the second season was carried out at the Central Laboratory ofNational Research Center, Giza. Essential oil GC/ Mass analysis was performed using a Hewlett-Packard 5890 A series 11 instrument equipped with flame ionization detector (FID) and a carbon wax fused silica column $(50 \mathrm{~m} \times 0.25 \mathrm{~mm}$. i. d., film thickness $0.32 \mu \mathrm{m})$. The initial column temperature was $50 \mathrm{C}^{\mathrm{o}}$ and held for 3 minutes, then raised to $60 \mathrm{c}^{\circ}$ by rate $3.0 \mathrm{C}^{\circ}$ per minute and raised to $260 \mathrm{C}^{\circ}$ by rate $3.0 \mathrm{C}^{\circ}$ per minute and hold at $260 \mathrm{C}^{\circ}$ for 5 minutes. The volatile oil components wereidentified by comparing their retentiontimes and mass spectrum with those ofstandards, NIST library of the GC-MSsystem, and literature data. Identifications were made by library searches combining MS and retention data of authentic compounds by comparison of their GC retention indices (RI) with those of the literature or with those of standards available in our laboratories (Adams, 2007).

\section{Antibacterial sensitivity test:-}

S. aureuswas investigated against 12 different antibiotics (Oxoid, UK) via Kirby-Bauer disc diffusion method.

\section{Assessing of antibacterial activity:-}

The antibacterial assay was carried out according to Alderman and smith 2001 with some changes. $S$. aureussuspension in PBSwas adjusted to be matched with 0.5 McFarlane standard tubes that equivalent to $1 \times 10^{8}$ $\mathrm{CFU} / \mathrm{ml}$. One hundred microliters were spread onto Mueller-Hinton agar (MHA, Oxoid, UK) plates on which wells with $8 \mathrm{~mm}$ diameter were made by cork borer. After 24 hours incubation, the inhibition zone diameter was measured in millimeters. The test was achieved in triplicates. The results were interpreted as weak action $(<10 \mathrm{~mm})$, moderate action $(10-15 \mathrm{~mm})$ and strong action $(>15 \mathrm{~mm})$ according to Adithepchaikarn et al., 2008.

\section{Estimation of minimum inhibition concentration (MIC) via micro-dilution technique:-}

Thyme oil was diluted in methanol to be in a concentration of $640 \mathrm{mg} / \mathrm{ml}$ and then to concentration $6400 \mu \mathrm{g} / \mathrm{ml}$ in Muller Hinton broth (MHB, Oxoid, Basingstoke, Hampshire, UK). Afterward, $100 \mu \mathrm{l}$ of the MHB dilution were diluted serially in 96-well plates (Corning Inc., Corning, NY, USA) to be ranged from 3200 to $100 \mu \mathrm{g} / \mathrm{ml}$, according to CLSI 2008. Next, $10 \mu \mathrm{l}$ of $S$. aureus suspension in saline $\left(1 \times 10^{8} \mathrm{CFU} / \mathrm{ml}\right)$ were added to each well of the micro-dilution plates. The inoculated plates were incubated at $37^{\circ} \mathrm{C}$ for 24 hours. The MIC was estimated as the lowest concentration at which no growth was shown in comparison with positive control wells (broth only). 


\section{In vivo assessment of antibacterial activity of thyme oil:-}

Forty-eight Swedish mice (Musmusculus) were divided into six groups of eight mice each as the following: Control (injected with $100 \mu \mathrm{l}$ saline), $S$. aureus infected (injected with $100 \mu \mathrm{l}$ of $1 \times 10^{8}$ colony-forming units (CFU) of $S$. aureus suspension), S. aureus infected plus antibiotic (Gentamycin, Sigma, USA) in dose $40 \mathrm{mg} / \mathrm{kg} / \mathrm{day}$, S. aureus infected plus 1 x MIC, $S$. aureus infected plus 2 x MIC and $S$. aureus infected plus 4 x MIC. To facilitate the infection, all treated groups were injected I/P with cyclophosphamide (Sigma, USA) (30mg/kg body weight) at 72 hours prior to infection. All groups were infected via subcutaneous injection. Five days later, the animals were sacrificed and spleen from individual animals was weighted and homogenized in phosphate-buffered saline (PBS), serially diluted 10-fold and streaked on Baird Parker plates (Oxoid, Basingstoke, Hampshire, UK), and incubated at $37^{\circ} \mathrm{C}$ for 24 hours to measure the bacterial load. The results were expressed as log (CFU/gm) of the spleen (Barquero-Calvoet al., 2013). Blood was collected and sera were prepared for estimation of hematological parameters and organ function tests, respectively.

\section{Haematological and Biochemical assays:-}

The collected blood was subjected to analysis by using automated blood analyzer (Abbott Labs Cell-Dyn 1800, USA) to determine the white blood cells count (WBCs), red blood corpuscles (RBCs), and haemoglobin ( $\mathrm{Hb}$ ) concentration. The above-prepared sera were subjected to estimate the following parameters using commercially available kits: alanine aminotransferase (ALT), total protein (TP), Albumin (Alb) (TECO DIAGNOSTICS, ANAHEIM, CA), urea and serum creatinine (BIOASSAY SYSTEM, HAYWARD, CA).

\section{Histopathological assessment:-}

Liver and kidneys morphology were characterized by light microscopy using routine hematoxylin and eosin (H\&E) staining. After sacrificing the mice, small pieces of liver and kidney were fixed in $10 \%$ formol-saline solution. The fixed tissues were embedded in paraffin wax, sectioned, and stained.

\section{Statistical analysis:-}

The obtained data were expressed as mean \pm SEM. The means of different groups were compared by using one-way analysis of variance (ANOVA) with Turkey's post-hoc test. The statistical analysis was performed by using SPSS version 21.0 (Chicago, IL). A $p$-value of $<0.05$ was considered statistically significant.

\section{Ethics:-}

The work was done with the respect recommended by $\mathrm{WHO} *$ for the animal welfare.

\section{Result:-}

The chromatographic analysis of the thyme essential oil revealed that Thymol (45.15\%) and $\rho$-cymene (25.31\%) are the major constituents as illustrated in Table (1).

Table 1:-The main constituents of the essential oil\% of Thymus vulgaris

\begin{tabular}{|l|l|}
\hline Compound & Percentage \\
\hline Thymol & 45.15 \\
\hline$\rho$-cymene & 25.31 \\
\hline Borneol & 5.06 \\
\hline Linalool & 4.10 \\
\hline Myrecen & 3.42 \\
\hline$\alpha$-Pinene & 3.21 \\
\hline$\gamma$-Terpinene & 2.80 \\
\hline Terpinol & 2.62 \\
\hline trans-Caryophyllene & 0.75 \\
\hline Cadinene & 0.55 \\
\hline Camphor & 0.51 \\
\hline Germacrene-D & 0.42 \\
\hline Carvacrol & 0.19 \\
\hline Caryophyllen oxide & 0.13 \\
\hline Carotol & 0.11 \\
\hline$\beta$-Bourbonene & 0.05 \\
\hline Total & $94.38 \%$ \\
\hline & \\
\hline
\end{tabular}


The antibiotic susceptibility of $\mathrm{S}$. aureus revealed that the used strain was sensitive to (CN, TOB, TET, VA, CTX and CIP) while was resistant to other used antibiotics. Based on the definition of Multidrug resistance (MDR) by Magiorakos et al 2012 as when the isolate is non-susceptible to at least one agent in $\geq 3$ antimicrobial categories, the used $S$. aureus strain is considered a multi drug resistant strain as shown in Table 2.

Table 2:-Antibiotic susceptibility of $S$. aureus

\begin{tabular}{|l|l|l|l|l|l|}
\hline Antibiotic & $\begin{array}{l}\text { Disc } \\
\text { content }\end{array}$ & $\begin{array}{l}\text { Inhibition } \\
\text { zone/mm }\end{array}$ & Antibiotic & $\begin{array}{l}\text { Disc } \\
\text { content }\end{array}$ & $\begin{array}{l}\text { Inhibition } \\
\text { zone/mm }\end{array}$ \\
\hline Amoxicillin- Clavulanic Acid (AMC) & $30 \mu \mathrm{g}$ & 7 & Gentamycin (CN) & $10 \mu \mathrm{g}$ & 38 \\
\hline Ciprofloxacin (CIP) & $5 \mu \mathrm{g}$ & 20 & Penicillin (P) & $10 \mu \mathrm{units}$ & 6 \\
\hline Clindamycin (DA) & $2 \mu \mathrm{g}$ & 5 & Piperacillin (PRL) & $100 \mu \mathrm{g}$ & 18 \\
\hline Oxacillin (OX) & $5 \mu \mathrm{g}$ & 8 & Tetracycline (TE) & $30 \mu \mathrm{g}$ & 30 \\
\hline Cefotaxime (CTX) & $5 \mu \mathrm{g}$ & 24 & Tobramycin (TOB) & $10 \mu \mathrm{g}$ & 34 \\
\hline Erythromycin (E) & $15 \mu \mathrm{g}$ & 6 & Vancomycin (VA) & $30 \mu \mathrm{g}$ & 30 \\
\hline
\end{tabular}

The activity of the thyme oil as antimicrobial agent against $S$. aureus strain was determined by using disc diffusion and MIC techniques. It is obvious that the oil had a strong antibacterial activity particularly at the concentration $100 \%$ whereas the inhibition zone was $28 \mathrm{~mm}$ in diameter. As the MIC was calculated as the lowest concentration causing inhibition of the visible growth of tested organism, the MICin our study was $0.025 \%$, as shown in Table 3 .

Table 3:-Antibacterial effect of thyme oil against $S$. aureus

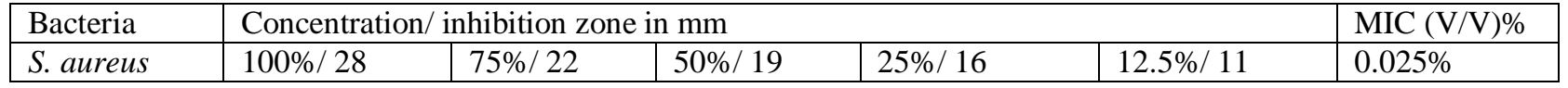

Thyme oil and bacterial count:-

As can be illustrated in fig ( 1 ), thyme essential oil confirmed to have in vivo antibacterial effect on tested $S$. aureus strain. Whereas there is no significant difference $(\mathrm{P}>0.05)$ between the result obtained from 2MIC and 4MIC treated groups with those of antibiotic treated group while 1MIC treated group showed lesser activity.

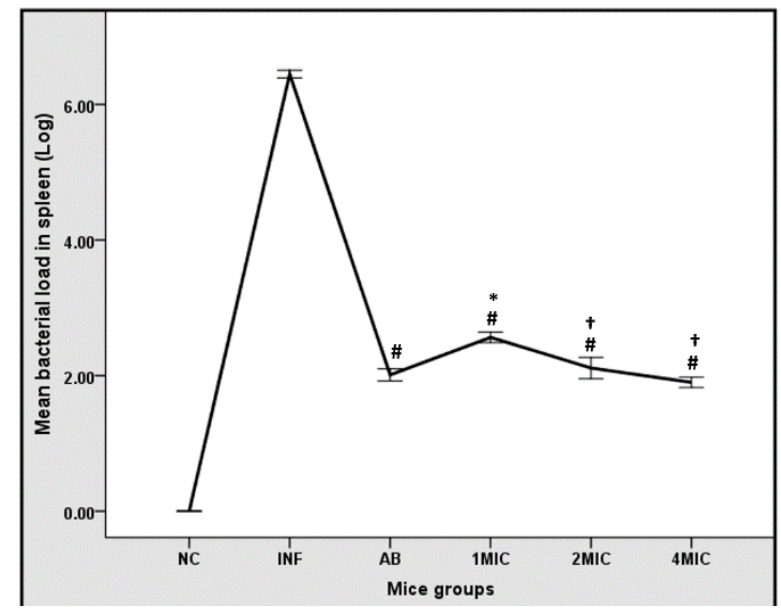

Fig 1:-Effects of double doses of MIC of thyme essential oil on splenic bacterial number.

\section{Effect of Thyme essential oil on hematologicalparameters:-}

As it is shown in fig ( 2 ), there were significant $(P<0.05)$ differences between the negative control group (INF) and all treated groups in terms of decrease $\mathrm{Hb}$ and $\mathrm{RBCs}$ and increase WBCs. Concerning $\mathrm{Hb}$ concentration and RBCs, 4MIC group showed significance $(P<0.05)$ decrease when compared with $\mathrm{NC}$ while $\mathrm{WBCs}$, it showed significance decrease when compared with 1MIC. 

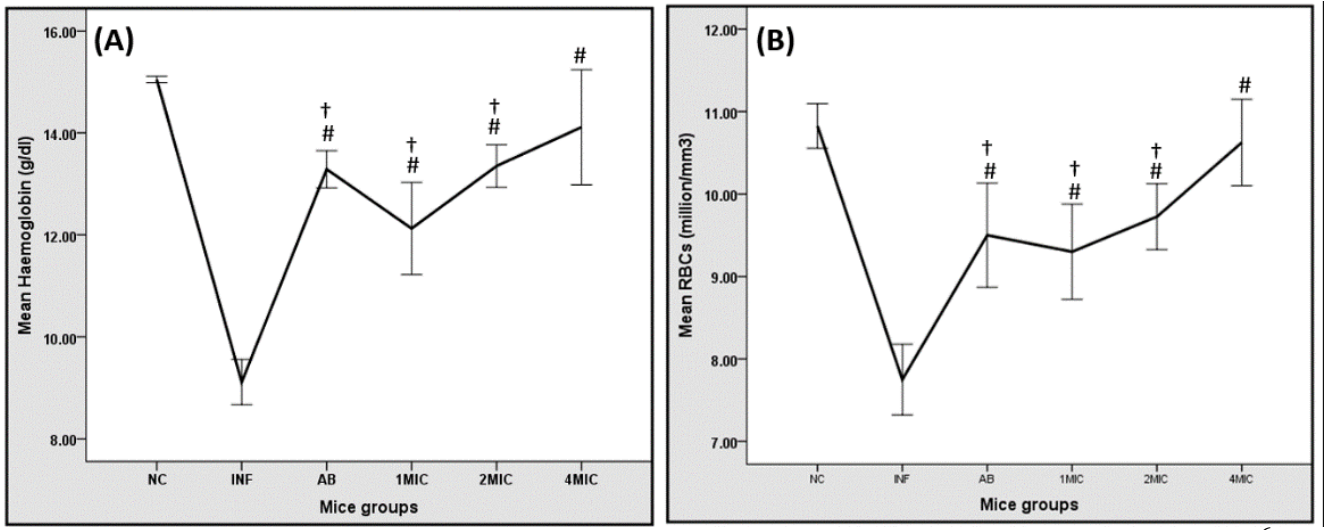

Fig 2:- Effects of double doses of MIC of thyme essential oil on: hemoglobin (g/dl). (B) RBCs $\left(10^{6} / \mathrm{mm}^{3}\right)$, and (C) WBCs $\left(10^{3} / \mathrm{mm}^{3}\right)$.

\section{Effect of thyme extract on liver and kidney function tests:-}

As illustrated in fig 3, concerning ALT, there was no significant difference $(P>0.05)$ between treated groups except in case of 4MIC group whereas it recorded the highest level. It was found that the infected group (INF) recorded the highest activity of the enzyme when compared with the other groups and followed by 4MIC group. Regarding serum creatinine, there was significant difference $(P<0.05)$ between the infected (INF) and the all treated groups. However, 2MIC group recorded the nearest enzyme activity when compared with the antibiotic treated (positive control) and normal (neutral) groups and followed by 4MIC group.
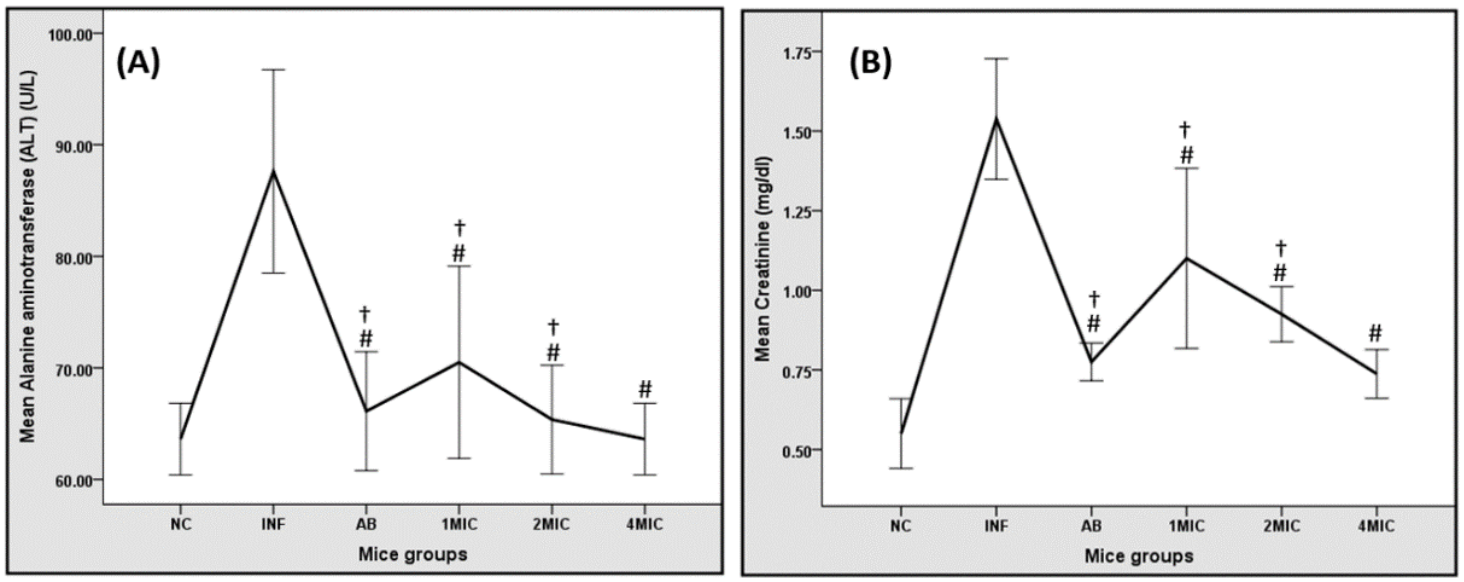

Fig 3:- Effects of double doses of MIC of thyme essential oil on liver (ALT) and kidney (creatinine)

functions.Diverse symbols show significant differences $(P<0.05)$ in different dosage groups in Duncan's multiple range test.

Effect of thyme extract on the histology of liver and kidney sections:-

Histopathological examination of hepatic sections (fig 4) revealed normal hepatocytes architecture of non-infected and all treated groups in different levels ranged from completely normal sections with normal hepatocytes with normal cytoplasm, nucleus, and central vein, mild signs of inflammation as congestion of central vein and hepatoportal blood vessels to vacuolar degeneration of the hepatocytes. The infected group showed the highest degree of inflammation and degeneration while 4MIC showed the best normal sections.

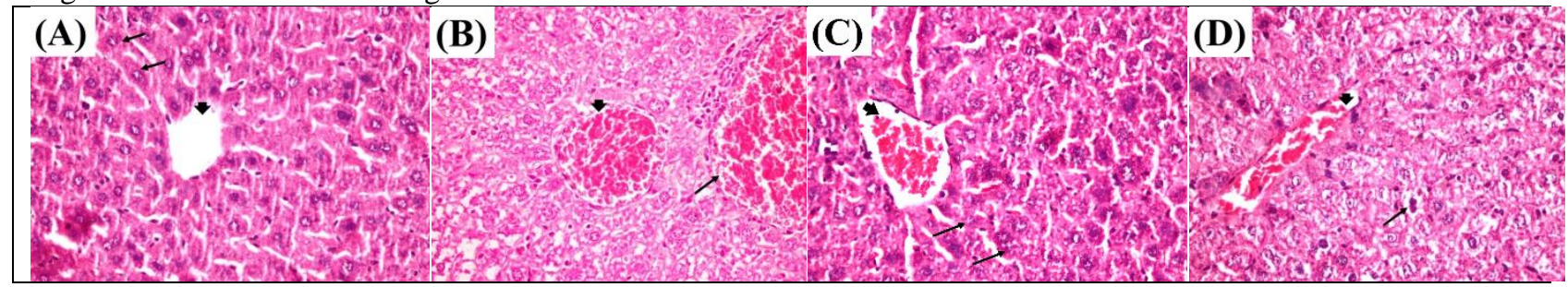

Fig 4:-Histopathological lesions in liver of treated and non-treated groups. 
Normal hepatocytes architecture(A), congestion of the central vein (arrow head) and hepatoportal blood vessel (arrows) (B), degenerated hepatocytes (arrow) with congested central vein (arrow head) (C) and vacuolation (ballooning degeneration) of the hepatocytes (arrows) and congested central vein (arrow head) (D) (H\&E X 400).

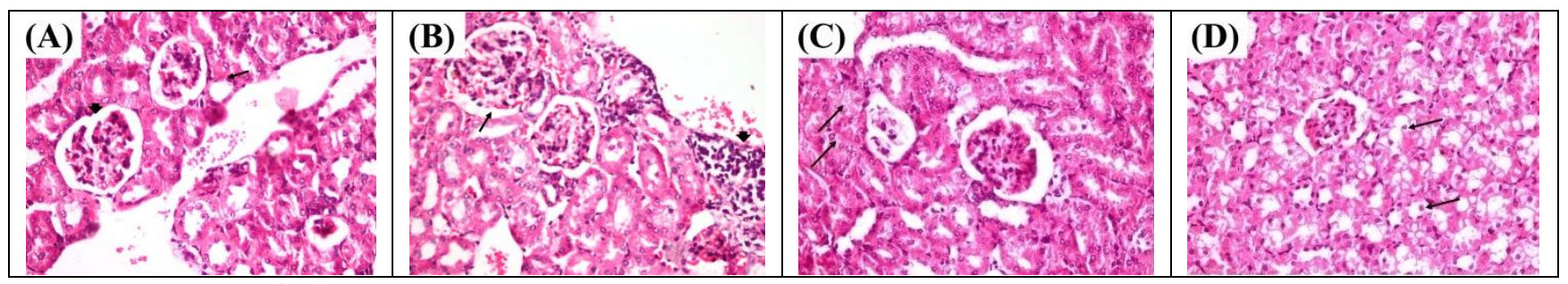

Fig 5:-Histopathological lesions in kidney of treated and non-treated groups.

Normal renal architecture (A); Kidneys showing congested glomerular capillaries (arrows) and leucocytes infiltrations (arrow head) (B); Kidneys showing degeneration of some renal tubules (arrows) (C) and Kidneys showing vacuolation of renal tubular epithelium (arrows) (D).

Almost the same trend of hepatic sections was shown in renal sections (fig 5) where all treated groups resemble to large extent the control group especially 4MIC group while 1MIC and 2MIC groups showed moderate signs of inflammation in the form of congestion of the interstitial blood vessels and degeneration of some convoluted tubules whereas infected group displayed the highest vacuolar degeneration of renal tubules.

\section{Discussion:-}

Essential oils have many applications in veterinary medicine such as insecticidal, anti-parasitic and treatment of infectious diseases in animals. Studies deal with antimicrobial properties of herbal plants essential oils against microorganisms with veterinary importance in vitro and in vivo are as yet restricted. Essential oils were applied on a large scale, in spite of their mechanism of action was not well clear. Because of their antimicrobial activity, they were mainly used practically to treat infections (Tiwariet al., 2009; Bakkaliet al., 2008 and Burt 2004). From our foregoing findings on antimicrobial sensitivity testing of thyme essential oil extract against $\mathrm{S}$. aureus, it was detected that the thyme essential oil has bactericidal activity with MIC $0.025 \%$ but their effectiveness varied according to the concentration (Table 3). Almost the same result was obtained in other studies (Ivanovicet al,.2012) against E. coli and Salmonella strains with MIC of $640 \mu \mathrm{g} \mathrm{mL-1}$ and in contrast with others (Imelouaneet al., 2009) who did not show any inhibition or selectivity towards Gram positive bacteria. In our work, this antimicrobial activity may be due to the presence of the greater concentration of phenolic compounds (Cetin et al., 2011; Rota et al., 2007. Skocibusicet al., 2006), thymol, $\rho$-cymene, borneol and $\alpha$-pinene (Tabancaet al., 2001; Vardar et al., 2003) in a percentage of $45.15,25.31,5.06$, and 3.21 , respectively.

In the present work, the antimicrobial activity of thyme essential oil may be attributed mainly to the high content of thymol (45.15\%) and p-cymene (25.31\%). Thymol had been established as bactericidal (Sikkemaet al., 1995) by a variety of mechanisms of action result in structural and functions modifications in the cytoplasmic membrane by affecting its permeability causing the release of $\mathrm{K}+$ ions and ATP. This in turn leads to cytoplasm coagulation, the denaturation of many enzymes involved in various carbon and nitrogen sources catabolism as well as the loss of ions and metabolites and then cellular death (Nazzaroet al., 2013; Burt and Reinders., 2003; Xuet al., 2008; Walsh et al., 2003). Regarding p-cymene, it is a monoterpene, some previous work revealed that it has antimicrobial activity when it is used alone (Bagamboulaet al., 2004; Aligianniset al., 2001 and Mann et al., 2000) and others had a different opinion when they described its antimicrobial effect as cofactor by increasing the antibacterial activity of other compounds such as, its derivative carvacrol (Rattanachaikunsoponet al., 2010 and Ulteeet al., 2002). Pcymene does not affect the membrane permeability but accepts its antimicrobial activity as it has a high affinity for bacterial membranes causing them to expand and decreasing their melting temperature (Cristaniet al., 2007), and affecting the membrane potential of intact bacteria (Ultee et al., 2002).

According to other studies (Sivropoulouet al., 1997; Carson and Riley., 1995 and Sur et al., 1991) camphor, terpinen and 1,8-cineole was principally responsible for the antibacterial activities of the plant essential oils. It is worth mentioning that the antimicrobial activities of essential oils are difficult to correlate to a specific compound due to 
their complexity and variability where their constituents concentrations may be affected by several factors (Nevaset al.,2004; Cakmakciet al., 2009 and Osman et al., 2009) such as water stress, the seasonal condition, chemical polymorphism, the origin, the stage of the collected plant material, and the method of extraction where there is no an international standardized technique for the evaluation of essential oils allows the use of different protocols, hampering the comparison of the results (Smith-Palmer et al., 1998 and Viuda-Martoset al., 2008). So, we used the M31-A3 protocol (CLSI; 2008) in our work as it is the most recommended among the technique found in the literatures. What is more, the activity of the essential oil was superior to the compound alone (Santurioet al., 2014). Such finding is explained by the fact that the high antimicrobial activity showed by essential oils results from the synergism of the major components (Höferlet al., 2009) and even trace elements as yet unidentified (Tepeet al.,2005; Goze, et al.,2009).

It is obvious from the result of disk diffusion test that the used strain of $S$. aureus considered a multi-drug resistant bacterium. This resistant may be attributed to many factors; one of those is possessing penicillinase enzyme (Kumar et al., 2011) which renders the bacteria resistant to $\beta$-lactam antibiotics (MRSA). Other factors of antibiotic resistance in the bacteria may be back to the genetically presence of antibiotic resistance genes on its chromosomes or plasmids, or getting them via a variety of genetic means as transformation, conjugation, and transduction or selecting the bacteria containing resistance genes by unwise use of penicillin or other antibiotics. All these processes promote and enhance the presence of antibiotic resistance and pathogenic S. aureus strains (Kumar et al., 2011).

Depending on the established data provided by in vitro antibacterial test results, in vivo study was conducted with a view to confirming the therapeutic effectiveness of the extract. The present study results revealed that the administration of thyme essential oil in different doses inhibited the growth, and reduced the viable S. aureus numbers. This ability of inhibition may be attributed to the existence of phytochemical groups as aforementioned in Table 1 . This result recommended that the antibacterial activity against $S$. aureus obtained in vitro was continued in vivo.

To check whether there were any statistically significance differences in the spleen bacterial load achieved by different treatments against $S$. aureus, two-way analysis of variance followed by Turkey`s test was applied. This analysis discovered significance variations (5\% level) among the different treatments where the effect of this essential oil against $S$. aureus gave a significant $(\mathrm{P}<0.05)$ result as an antibacterial agent when comparing infected control groups with all treatments where 4MIC group was the best group in inhibiting the bacteria followed by 2MIC and 1MIC. This indicates that the thyme essential oil has inhibitory effect on S. aureus and the bacterial inhibition increased directly with the thyme essential oil concentration, as shown in Fig. 1

On the other hand, it must be taken into account that the highest thyme oil concentration (4MIC) had no bad effect on the hemoglobin concentration and RBCs count (Fig. 2) as well as the vital organs as liver and kidneys as indicated by the normal ALT and creatinine levels which commonly used as markers of liver and kidney degeneration (Olaleyeet al., 2014; Suganthiet al., 2013 and Bidieet al., 2010), respectively (Fig. 3). High level of this enzyme in the infected untreated group was backed to the infection. The hepatic damage was further supported by histopathological findings in liver and kidney sections (Fig. 4 and 5). The hepatic sections of infected untreated groups revealed signs of inflammation in the form of dilatation and congestion of hepatoportal blood vessels with ballooning degeneration of hepatocytes. At doses of 1MIC, 2MIC and 4MIC liver and kidney sections revealed a significant difference $(P<0.05)$ from the infected untreated group and showed the normal appearance similar to large extent the control group particularly in the case of 4MIC group. Therefore, the thyme essential oil at these doses not only overcome the infection but might correct the harmful effect of infection on hepatic and renal cells. Nonetheless, the major signs of hepatic and renal damage as necrosis and apoptosis (Eroschenko, 2000) were not detected in our study, the same findings were observed in another previous study (Talaet al., 2015).

\section{Conclusion:-}

The inclusive results of our study provide baseline data for the possible use of essential oils in the remedy of Staphylococcus aureus infection and can be considered the best alternative to the antimicrobial drugs in facing the drug resistance development. Beside the antimicrobial activity, the information recorded from using doubled doses showed that the thyme essential oil considered safe in the treatment of bacterial infection. This effect was dose dependent, therefore, there is need to conduct experiments on large scale and on large animals, both in vitro and in vivo, to establish the maximum safe level of this EO against bacteria and also, it is necessary to further investigate 
the interaction between the pathogenic bacteria and thyme essential oil and its impact on the development of resistance.

\section{Acknowledgements:-}

The author gratefully acknowledges the financial support from the Desert Research Center (DRC), Cairo, Egypt.

\section{References:-}

1. Aligiannis, N., Kalpoutzakis, E., Mitaku, S. and Chinou, I.B. (2001) .Composition and antimicrobial activity of the essential oils of two Origanum species. J. Agric. Food Chem. 49: 4168-4170.

2. Bagamboula,.C.F., Uyttendaele, M. and Debevere, J.( 2004). Inhibitory effect of thyme and basil essential oils, carvacrol, thymol, estragol, linalool and p-cymene towards Shigellasonnei and S. flexneri. Food Mic. 21: 3342.

3. Bakkali, F., Averbeck, S., Averbeck, D. and Idaomar, M. (2008). Biological effects of essential oils - a review. Food Chem Toxicology. 46(2): 446-475.

4. Barquero-Calvo E., Chacón-Díaz C., Chaves-Olarte E. and Moreno, E. (2013). Bacterialn counts in spleen. Bio Protoc .3:e954.

5. Bidie, ADP.,Koffi, E., Yapi, FH., Yémié, AA., Djaman, JA.andGuede-Guina, F.( 2010). Evaluation of the toxicity of a methanolic total extract of Mitragyna ciliate a natural anti-malaric. Int J BiolChem Sci. 4(5): 150918.

6. Burt, S. (2004). Essential oils: their antibacterial properties and potential applications in foods - a review. Int . J. Food Microbiol. 94(3): 223-253.

7. Burt, S.A.andReinders, R.D. (2003). Antibacterial activity of selected plant essential oils against Escherichia coli O157:H7. Lett. Appl. Microbiol. 36:162-167.

8. Çakmakçı, R ., Erdoğan, Y., Erdoğan ,Ü., Kotan, R. and Mete E. (2009). Research on essential oil content and components of wild ecotype Origanumacutidens in diff erent ecologies of the İspir Region. Int. Rural Development Symposium' 09 (Yildırım A and Erdoğan Ü, Ed.). September 25-27, 2009 İspir Erzurum, Turkey.

9. Carson, C.F. and Riley, T.V. (1995). Antimicrobial activity of the major components of the essential oil of Melaleucaalternifolia. J. Appl. Bacteriol. 78: 264-269.

10. Cetin ,B., Cakmakci, S. and Cakmakci R. (2011a). The investigation of antimicrobial activity of thyme and oregano essential oils. Turk J Agric For 35(2):145-154.

11. Chaudhry, NMA. and Tariq, P.( 2006). Bactericidal activity of black pepper, bay leaf, aniseed and coriander against oral isolates. Pak. J. Pharm. Sci. 19(3) : 214-218.

12. Cristani, M., D’Arrigo, M., Mandalari, G., Castelli, F., Sarpietro, M.G., Micieli, D.,Venuti, V., Bisignano, G., Saija, A. and Trombetta, D.( 2007). Interaction of four monoterpenes contained in essential oils with model membranes:implications for their antibacterialactivity. J. Agric. Food Chem. 55: 6300-6308.

13. Dapkevicius, A., V.T. A. Van Beek, G.P. Lelyveld, A. Van Veldhuizen, A. DeGroot, J.P.H. Linssen. and R. Venskutonis.( 2002). Isolation and structural elucidation of radical scavengers from Thymus vulgaris leaves. J. Nat. Prod. 65(6): 892-896.

14. Eroschenko, VP. (2000). Di Fiore's atlas of histology with functional correlations 9th ed. Philadelphia: Lippincott. Williams and Wilkins .

15. European Pharmacopoeia, 1996. Saint Ruffine:Conseil de l'EuropeMaisonneuve S.A. NCCLS. (1999) . National Committee for Clinical Laboratory Standards, Performance Standards for Antimicrobial Susceptibility Testing, 6th edition . Approved Standards, M2-A6, Wayne, Pennsylvania.

16. Goze,I.A., Alim, A.Centinum, S.A., Durmus ,N.,Vural,N .and Goze,H .(2009).Chemical composition and antioxidant, antimicrobial, antispasmodic activities of the essential oil of thymus fallaxfisch.Mey. J.ofMed.Plants Res.3:174-178.

17. Höferl ,M., Buchbauer ,G., Jirovetz ,L., Schmidt E., Stoyanova A., Denkova , Z., Slavchev ,A. and Geissler, M. (2009). Correlation of antimicrobial activities of various essential oils and their main aromatic volatile constituents. Journal of Essential Oil Research. 21(5): 459-464.

18. Imelouane, B., Amhamdi, H., Wathelet ,J., Ankit ,M., Khedid ,K and El Bachiri, A. (2009) chemical composition and antimicrobial activity of essential oil of thyme ( vulgaris) from eastern Morocco. Int $\mathrm{J}$ Agric Biol. 11: 205-8.

19. Ivanovic, J., Misic, D., Zizovic ,I. and Ristic, M.( 2012). In vitro control of multiplication of some foodassociated bacteria by thyme, rosemary and sage isolates. Food Control. 25(1): 110-116. 
20. Jaber ,NN., Abdul Wahid, AT. andJasim, AS.( 2012). Antimicrobial efficacy of oregano extracts. Bas. J. Vet. Res. 11(1): 23-31.

21. Kumar, R., Yadav ,BR. and Singh, RS. (2011). Antibiotic resistance and pathogenicity factors in Staphylococcus aureus isolated from mastiticSahiwal cattle. J. Biosci. 36(1): 175-188.

22. Mann, C.M., Cox, S.D. and Markham, J.L. (2000). The outer membrane of Pseudomonas aeruginosa NCTC6749 contributes to its tolerance to the essential oil of Melaleucaalternifolia (tea tree oil). Lett. Appl. Microbiol. 30:294-297.

23. Nazzaro, F., Fratianni, F., De Martino, L., Coppola, R. and De, Feo. V. (2013). Effect of essential oils on pathogenicbacteria. Pharmaceuticals (Basel) .6:1451-74.

24. Nevas, M., Korhonen, A., Lindstrom, M., Turkki, P. and Korkeala ,H. (2004). Antibacterial efficiency of Finnish spice essential oils against pathogenic and spoilage bacteria. J Food Prot .67, 199-202.

25. Olaleye, MT., Amobonye, AE.,Komolafe ,K. and Akinmoladun ,AC. (2014). Protective effects of Parinaricuratellifolia flavonoids against acetaminophen-induced hepatic necrosis in rats. Saudi J BiolSci .21(5): 486-92.

26. Osman, Y.A.H., Yaseen, E.M. and Farag, M.M. ( 2009). Antimicrobial Effect of Some Essential Oils Mixtures Journal of Applied Sciences Research.5 (9):1265-1276.

27. Omidbaigi, R. and Nejad, R.A. (2000). The influence of nitrogenfertilizer and harvested time on the productivity of Thymus vulgaris L. Inter. J. Horti. Sci., 6 (3): 43-46.

28. Prabuseenivasan, S., M, Jayakumar and S, Ignacimuthu. (2006) . In vitro antibacterial activity of some plant essential oils. BMC ComplementaryAltern. Med. 6: 39.

29. Rattanachaikunsopon, P. and Phumkhachorn, P. (2010). Assessment of factors influencing antimicrobial activity of carvacrol and cymene against Vibrio cholerae .food. J. Biosci. Bioeng. 110: 614-619.

30. Rota, M.C., Herrera, A., Martinez, R.M., Sotomayor, J.A. and Jordan, M.J. ( 2007). Antimicrobial activity and chemical composition of Thymus vulgaris, Thymus zygis and Thymus hyemalis essential oils. Food Cont. 19: 681-687.

31. Santurio, DF., Kunz de Jesus, FP., Zanette, RA., Schlemmer, KB., Fraton, A. and Martins Fries, LL. (2014) . Antimicrobial Activity of the Essential Oil of Thyme and of Thymol against Escherichia coli Strains. Acta Sci. Vet. 42:1234.

32. Sikkema, J., de Bont, J.A.M. and Poolman , B. (1995) . Mechanisms of membrane toxicity of hydrocarbons. Microbiol. Rev. 59: 201-222.

33. Sivropoulou, A., Nikolaou, C., Papanikolaou, E., Kokkini, S., Lanaras, T. and Arsenakis, M. (1997). Antimicrobial cytotoxic and antiviral activities of Salvia fruticosa essential oil. J. Agric. Food Chem. 45: 31973201.

34. Skocibusic, M., Bezic, N. and Dunkic, V.( 2006). Phytochemical composition and antimicrobial activities of essential oils from Saturejasubspicata Vis. Growing in Croatia. Food Chem. 96: 20-28.

35. Smith-Palmer, A., Stewart, J. and Fyfe, L. (1998). Antimicrobial properties of plant essential oils and essences against five important food -borne pathogens. Letters in Applied Microbiology . 26(2): 118-122.

36. Suganthi, V., Gowri, S. and Gurusamy, K. (2013) Hepatoprotective activity of Cayratiacarnosa on liver damage caused by lead acetate in rats. J Nat Prod Plant Resour. 3(2): 76-9.

37. Sur, S.V., Tuljupa, F.M. and Sur, L.I. (1991). Gas chromatographic determination of monoterpenes in essential oil medicinal plants. J. Chromatograph. 542: 451-458.

38. Tabanca, N., Kirimer, N., Demirci, B., Demirci , F. and Baser, K.H.C. (2001) . Composition and antimicrobial activity of the essential oils of Micromeriacristata subsp. phyrgia and the enantiomeric distribution of borneol. J. Agric. Food Chem. 49: 4300-4303.

39. Talaa, DS.,Gatsinga , D., Fodouopa , SP., Fokunangc, C., Kengnia, F. and Djimelia , M. N.( 2015) . In vivo anti-salmonella activity of aqueous extract of Euphorbia prostrataAiton (Euphorbiaceae) and its toxicological evaluation. Asian Pac J Trop Biomed. 5 (4): 310-318.

40. Tepe, B., Sokmen, M., Akpulat, HA., Daferera ,D., Polissiou ,M. and Sokmen ,A . (2005) .Antioxidative activity of the essential oils of Thymussipyleus subsp. sipyleus var. sipyleus and Thymus sipyleussubsp.sipyleus var. rosulans. J Food Eng 66: 447-454.

41. Tiwari, BK., Valdramidis ,VP., O’Donnel, CP., Muthukumarappan, K., Bourke, P. and Cullen, PJ. (2009) . Application of natural antimicrobialsfor food preservation. J. Agric. Food Chem. 57:5987-6000.

42. Ultee, A., Bennik, M.H. and Moezelaar, R. (2002). The phenolic hydroxyl group of carvacrol is essential for action against the food-borne pathogen Bacillus cereus. Appl. Environ. Microbiol. 68: 1561-1568. 
43. Vardar, UG.,Candan, F., Sokmen, A., Daferera, D., Polissiou, M., Sokmen, M., Donmez, E. and Tepe, B. (2003) . Antibacterial and antioxidant activity of the essential oil and methanol extracts of Thymus pectinatusFisch. Mey var. pectinatus (Lamiaceae). J. Agric. Food Chem., 51: 63-67.

44. ViudaMartos, M., Navajas ,R., López ,F. and Álvarez ,P. (2008). Antibacterial activity of different essential oils obtained from spices widely used in Mediterranean diet. Int. J. of Food Sci. and Tec. 43(3): 526-531.

45. Walsh, SE.,Maillard, JY., Russell, AD., Catrenich, CE. Charbonneau, DL. andBartolo, RG. (2003) . Activity and mechanisms of action of selected biocidal agents on Gram-positive and negative bacteria. J. Appl. Microbiol. 94: 240-247.

46. Xu, J., Zhou, F., Ji, BP., Pei, RS. and Xu, N. ( 2008). The antibacterial mechanism of carvacrol and thymolagainstEscherichia coli. Lett. Appl. Microbiol. 47: 174-179. 